Available online at http://jurnal.goretanpena.com/index.php/JSSR

\title{
PERANCANGAN SISTEM DAN DESAIN UNDANGAN DIGITAL MENGGUNAKAN METODE WATERFALL BERBASIS WEBSITE (STUDI KASUS: ASCO JAYA)
}

\author{
Barany Fachri ${ }^{1}$, Risky Wahyu Surbakti ${ }^{2}$ \\ Universitas Pembangunan Panca Budi, Medan \\ e-mail: barany_fachri@dosen.pancabudi.ac.id ${ }^{1}$, riskysurbakti@gmail.com²
}

\begin{abstract}
PT. Asco jaya is one of the individual companies engaged in providing paper invitation design and printing services, books and other paper prints located on medan mosque road.In competition in the industrial 4.0 world in the printing world PT. Asco Jaya develops paper invitations into digital invitation websites where consumers place orders according to the design of invitations selected by consumers from the website.To answer the development of PT. Asco jaya then the author built a digital invitation ordering and design system using the waterfall method.Waterfall method is a method that is considered appropriate and appropriate in developing the digital invitation ordering and design system of PT. Asco jaya because the waterfall method is a method that makes it easier to control and schedule the process of developing the system.The result of this study was to build a digital invitation ordering and design system using the waterfall method.
\end{abstract}

Keywords: Digital Invitation System and Design, Waterfall Method.

\begin{abstract}
Abstrak: PT. Asco jaya adalah salah satu perusahaan perorangan yang bergerak dalam menyediakan jasa desain dan cetak undangan kertas, buku dan cetak kertas lainnya yang berada di jalan Mesjid Medan. Dalam persaingan dimasa industri 4.0 dalam dunia percetakan PT. Asco Jaya mengembangkan undangan kertas menjadi undangan digital website yang mana konsumen melakukan pemesanan sesuai desain undangan yang dipilih konsumen dari website. Untuk menjawab pengembangan PT. Asco jaya maka penulis membangun sistem pemesanan dan desain undangan digital menggunakan metode waterfall. Metode waterfall merupakan metode yang dianggap pantas dan tepat dalam mengembangkan sistem pemesanan dan desain undangan digital PT. Asco jaya dikarenakan metode waterfall merupakan metode yang mempermudah dalam melakukan kontrol dan menjadwal proses pengerjaan pengembangan sistem. Hasil dari penelitian ini adalah membangun sistem pemesanan dan desain undangan digital menggunakan metode waterfall.
\end{abstract}

Kata kunci: Sistem Dan Desain Undangan Digital, Metode Waterfall.

\section{PENDAHULUAN}

Pada era revolusi industri 4.0 semua perangkat akan membutuhkan koneksi internet dan dengan internet memberi kemudahan bagi manusia. Kehadiran internet seolah menggeser kebiasaan mengakses media lama yang sudah ada. Namun hal itu juga sedikit dibenarkan karena dengan internet semua terasa mudah. Internet juga mengubah pola hidup seseorang. Akses internet cepat ditambah telepon genggam yang berlayar lebar menjadikan semua mudah. Banyak hal bisa dikerjakan menggunakan telepon genggam terkoneksi internet. Aplikasi di telepon genggam menjadikan seseorang dimudahkan namun di sisi lain juga menjadi ketergantungan. (Norhabiba dan Putri, 2018)

Penelitian terdahulu dilaksanakan oleh Andika dan Eva (2020) yang 
Available online at http://jurnal.goretanpena.com/index.php/JSSR

melakukan penelitian dengan judul Perancangan Sistem Informasi Pemesanan Undangan Dan Yasin Pada CV. Kurnia Berbasis Web. Penelitian tersebut menggunakan metode metode pendekatan menggunakan sistem berorientasi objek sementara metode pengembangan sistem yang digunakan adalah Waterfall model. Sistem model mengunakan metode Unifield Modeling Languange (UML).

Penelitian selanjutnya dilakukan oleh Minda Septian et.al (2019) dengan judul Metode Waterfall Penjualan Mebel Properti Berbasis Web. Dalam penelitian tersebut menggunakan metode waterfall untuk membangun aplikasi penjualan mebel properti berbasis web.

Pada penelitian ini metode yang digunakan adalah metode waterfall, metode waterfall adalah sebuah metode pengembangan sistem dimana antar satu fase ke fase yang lain dilakukan secara berurutan. Dalam proses implementasi metode Waterfall ini, sebuah langkah akan diselesaikan terlebih dahulu dimulai dari tahapan yang pertama sebelum melanjutkan ke tahapan yang berikutnya.

Menurut B Fachri et.al (2019) Perancangan merupakan upaya untuk mengonstuksi sebuah sisteni yang memberikan upaya kepuasan (mungkin informal) akan spesifikasi kebutuhan fungsional, memenuhi target, memenuhi kebutuhan secara implisit atau eksplisit dan segi performansi maupun pengguna sumber daya, kepuasan batasan pada proses desain dan segi biaya, waktu, dan perangkat.

Dalam bahasa Inggris perancangan adalah salah satu arti dalam desain, bisa di jabarkan arti kata desain adalah ilmu yang berhubungan dengan suatu

Perencanaan atau perancangan. Biasanya berbentuk gambar yang nantinya diwujudkan dalam bentuk sebenarnya.

Tujuan yang ingin dicapai penulis dalam sistem pemesanan dan desain undangan website pada Asco Jaya ini adalah :
1. Agar lebih memudahkan dalam melakukan pemesanan dan desain undangan website yang dapat bekerja lebih cepat dari cara manual dengan menggunakan buku.

2. Agar pengguna dapat melakukan pembelian undangan website dengan cara online.

Desain sendiri adalah suatu disiplin atau mata pelajaran yang tidak hanya mencakup eksplorasi visual, tetapi terkait dan mencakup pula dengan aspek-aspek seperti kultural-sosial, filosofi, teknis dan bisnis. Aktivitasnya termasuk dalam desain grafis, desain industry, arsitektur, desain interior, desain produk dan profesiprofesi lainnya

1. Tujuan Perencanaan

Studi desain secara luas dapat disempitkan berfokus pada bentuk dan fungsi dasar pemikiran, kebutuhan, maksud dan tujuan kegunaan serta implikasi bentuk. Dengan lebih mamahami fungsi bentuk (form) kita lebih memahami bagaimana bentuk dapat menghubungkan kita ke orang lain dan ke dunia. Bentuk memiliki banyak arti, kebanyakan arti tersebut berakar dari kata latin, forma yang berasal dari bahasa yunani berarti bentuk, struktur, ide. Pada intinya bentuk adalah gabungan elemenelemen visual dasar, yaitu ukuran, warna dan tekstur dan lebih dari sekedar shape. Dalam desain komunikasi visual tidak hanya berfungsi mekanikal tetapi ada fungsi lainnya, yaitu memberi inspirasi, informasi dan menggerakan kita untuk beraksi.

2. Funsi Perencanaan

Perancangan disini digunakan untuk bagaimana merancang suatu produk atau jasa untuk menjadi hal yang lebih baik dari sebelumnya, dimana membutuhkan tampilan yang sangat menarik untuk desain promosi dengan menganut desain komunikasi visual.

\section{METODE}


Available online at http://jurnal.goretanpena.com/index.php/JSSR

Langkah awal yang dilakukan penyusun dalam membangun sistem informasi adalah dengan menentukan model sistem informasi yang akan dipakai. Dalam hal ini penyusun menentukan atau memilih model sistem informasi tersebut dengan salah satu model sistemnya menggunakan model sistem waterfall.

Metode pengumpulan data yang dilakukan dalam penelitian ini adalah:

1. Observasi

Pengumpulan data dengan melakukan tanya jawab kepada pemilik PT. Asco Jaya tentang pemesanan dan desain undangan digital.

\section{Studi Pustaka}

Pengumpulan data dengan menggunakan atau mengumpulkan sumber-sumber tertulis, dengan cara membaca, mempelajari dan mencatat hal-hal penting yang bersumber dari buku, jurnal dan internet yang berhubungan dengan masalah yang sedang dibahas guna memperoleh gambaran secara teoritis

3. Analisa Kebutuhan

Pada tahap ini dilakukan identifikasi masalah pada sistem yang sedang berjalan. Dengan demikian, diharapkan peneliti dapat menemukan permasalahan yang terjadi pada prosesnya sehingga peneliti dapat mencari solusi dari permasalahan tersebut

4. Mendesain Sistem

Pada Tahap ini dilakukan mendesain sistem dengan menggunakan permodelan UML (Unified Modelling Language) dan pada tahap ini dilakukan perancangan antarmuka aplikasi yang akan dibuat

5. Implementasi Sistem

Implementasi sistem dilakukan sesuai desain dan rancangan antarmuka aplikasi yang akan dibangun. Pada tahap ini melakukan pengkodingan atau pembuatan program aplikasi yang dirancang dapat digunakan oleh pengguna

6. Pengujian Sistem

Pada tahap ini aplikasi yang sudah dirancang sebelumnya telah selesai dan dilakukan tahapan pengunjian aplikasi apakah ada error atau kerusakan pada aplikasi yang telah dirancang.

\section{HASIL DAN PEMBAHASAN}

Sebuah program harus bebas dari kesalahan-kesalahan atau error. Oleh karena itu, program harus diuji coba terlebih dahulu untuk menemukan kesalahan-kesalahan yang mungkin terjadi, pengujian ini menggunakan metode pengujian black box. Pengujian blackbox berfokus persyaratan fungsional perangkat lunak.

Rencana pengujian yang akan dilakukan dengan menguji sistem secara blackbox. Rencana pengujian selanjutnya terlihat pada table dibawah ini

Untuk tabel skor jawaban ME2-ME4 :

\begin{tabular}{|c|l|l|}
\hline Menu & \multicolumn{1}{|c|}{ Detail } & Jenis Uji \\
\hline $\begin{array}{c}\text { Pemilihan } \\
\text { tema } \\
\text { undangan }\end{array}$ & $\begin{array}{l}\text { Memilih } \\
\text { tema }\end{array}$ & Blackbox \\
undangan & \\
\hline
\end{tabular}

Kasus dan pengujian edngan blackbox dengan metode waterfall :

Pengujian Pemilihan Tema Undangan

\begin{tabular}{|c|c|c|c|}
\hline \multicolumn{4}{|c|}{ Kasus dan hasil uji data waterfall } \\
\hline $\begin{array}{c}\text { Data } \\
\text { masukan }\end{array}$ & $\begin{array}{c}\text { Yang } \\
\text { diharapk } \\
\text { an }\end{array}$ & $\begin{array}{c}\text { Penga } \\
\text { matan }\end{array}$ & $\begin{array}{c}\text { Kesimp } \\
\text { ulan }\end{array}$ \\
\hline $\begin{array}{c}\text { Pemilihan } \\
\text { Tema } \\
\text { Undangan }\end{array}$ & $\begin{array}{c}\text { Menamp } \\
\text { ilkan } \\
\text { Tema } \\
\text { Undang } \\
\text { an }\end{array}$ & $\begin{array}{c}\text { Meng } \\
\text { isi } \\
\text { Data }\end{array}$ & $\begin{array}{c}\text { Diterim } \\
\text { a }\end{array}$ \\
\hline Kasus dan hasil uji data (tidak normal) \\
metode waterfall \\
\hline Data & $\begin{array}{c}\text { Yang } \\
\text { diharapk } \\
\text { Masukan }\end{array}$ & $\begin{array}{c}\text { Peng } \\
\text { matan }\end{array}$ & Kesimp \\
& ulan \\
Pemilihan & $\begin{array}{c}\text { Penggun } \\
\text { a tidak } \\
\text { Tema } \\
\text { Undangan } \\
\text { temilih }\end{array}$ & $\begin{array}{c}\text { Hasil } \\
\text { tidak } \\
\text { bisa } \\
\text { mengi } \\
\text { undanga } \\
\text { si } \\
\text { data }\end{array}$ & \\
\hline
\end{tabular}


Available online at http://jurnal.goretanpena.com/index.php/JSSR

Hasil pengujian dari pengujian blackbox yang telah dilakukan, menunjukkan bahwa aplikasi yang dibangun sudah memenuhi persyaratan fungsional. Akan tetapi, pada prosesnya masih memungkinkan untuk terjadi kesalahan. Secara fungsional sistem yang telah dibangun sudah dapat menghasilkan keluaran yang diharapkan.

Setelah melaui proses perancangan dan implementasi dari data-data yang diperoleh melalui pengumpulan data sebelumnya dihasilkan sebuah aplikasi Undangan yang menggunakan bahasa PHP dan MySql. Adapun tampilan dari aplikasi tersebut dapat dilihat pada gambar berikut.

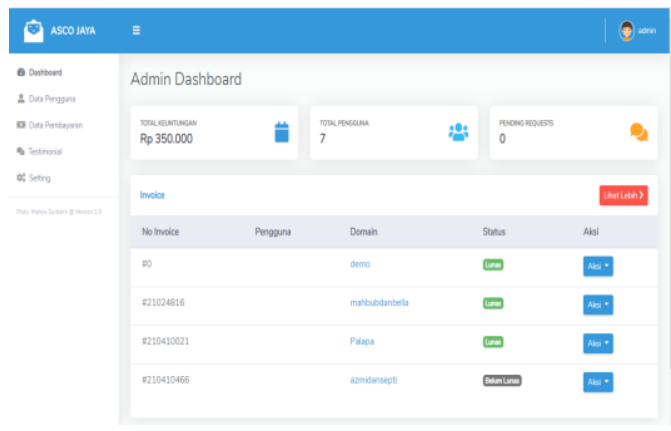

\section{Gambar Halaman Utama}

Pada gambar tersebut memuat tentang konfirmasi dan aktifkan yang dimana bisa kemenu pembayaran.

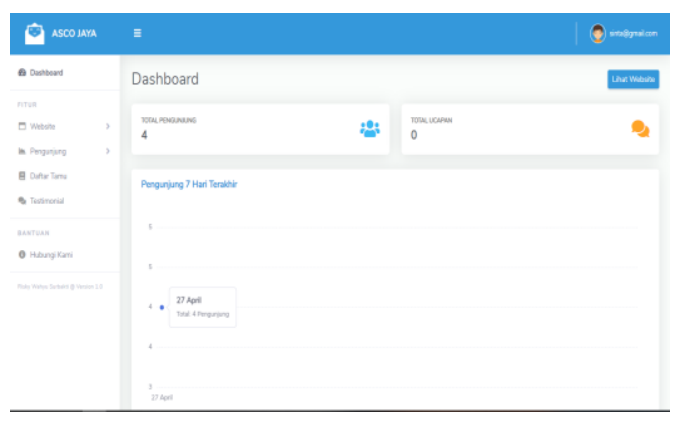

\section{Gambar Menu Utama User}

Tampilan menu home user terdiri dari logo asco jaya, icon admin, menu- menu, total pengunjung dan total penguncung dan grafik dari keduanya :

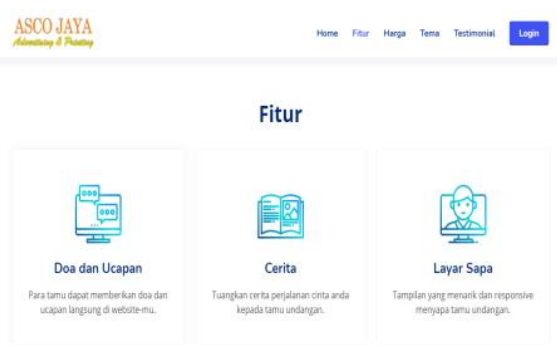

\section{Gambar Menu Fitur}

Tampilan fitur terdapat pada tampilan website saja dan bersifat statis. Tampilan ini berfungsi sebagai fitur yang ditawarkan pada website ini, yaitu: doa dan ucapan, cerita dan layar sapa.

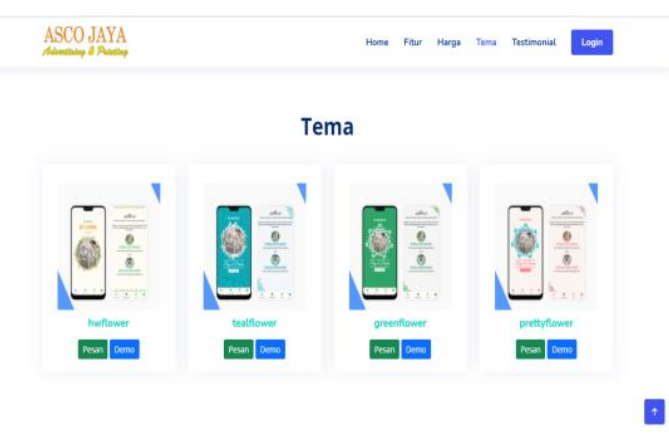

Gambar Menu Tema

Juga dapat ditampilkan menu testimoni dalam bentuk yang mudah dilihat seperti di bawah ini :

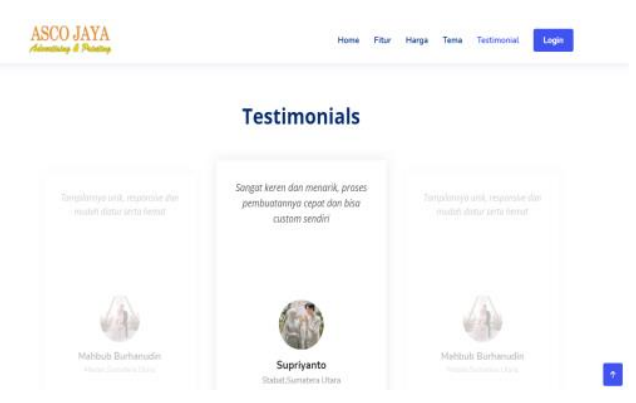

Gambar Menu Testimoni 
Available online at http://jurnal.goretanpena.com/index.php/JSSR

\section{SIMPULAN}

Berdasarkan hasil dari perancangan sistem pemesanan dan desain undangan digital website studi kasus PT. Asco Jaya, maka didapat beberapa kesimpulan seperti berikut:

1. Aplikasi untuk pemesanan dan desain undangan digital website dibangun dengan menggunakan software studio code dengan menuliskan kode program dengan bahasa pemrograman PHP.

2. Dengan adanya aplikasi pemesanan dan desain undangan digital website memudahkan pengguna untuk mendesain sesuai keinginan.

3. Aplikasi pemesanan dan desain undangan digital website menerapkan metode waterfall agar pengembangan lebih efektif dan efesien

\section{DAFTAR PUSTAKA}

Aprilla, E. (2020). Desain dan Implementasi Sistem Pemesanan Makanan dan Program Promosi Penjualan pada Mie Pangsit Ayam Sudi 189. Universitas Internasional Batam

Andika., \& Zuraidah, E. (2020). Perancangan Sistem Informasi Pemesanan Undangan dan Yasin Pada CV. Kurnia Berbasis Web. Jurnal Infortech Volume 2 No. 1 Juni 2020

Fachri, B., Khairul., Hariadi,. (2019). Sistem Pendukung Keputusan Penentuan Kelayakan Penerimaan Sertifikasi Guru Pada (Sd Negeri 104214 Deli Tua) Menggunakan Metode Topsis. Prosiding Seminar Nasional Riset Information Science (SENARIS). September 2019.

Janah, E, M. (2019). Sistem Informasi Pemesanan dan Pengiriman
Obat Berbasis Mobile (Studi Kasus PT. Wansa Turga Citra Bandar Lampung). Institut Informatika dan Bisnis Darmajaya.

Norhabiba, F., \& Putri, S, A, R. (2018). Pengaruh Intensitas Akses Internet Terhadap Kualitas Interaksi Sebaya Pada Mahasiswa Untag Surabaya. Jurnal Komunikasi Dan Kajian Media Volume 2, Nomor 2, Oktober 2018: 13-21.

Ramadhani, M., Rosely, E., dan Wijayanto, P, W. (2019). Web Based Application Of Convection Product Booking At Greens Production Bandung. eProceeding of Applied Science: Vol.5, No.3 Desember 2019

Septiani, M., Rahmanto, S., Sofica, V., \& Ningsih, R. (2019). Metode Waterfall Penjualan Mebel Properti Berbasis Web. Jurnal Teknologi Informasi Mura. Vol. 11 No.02, Desember 2019.

Syahputra, Z. (2020) "Website Based Sales Information System With The Concept Of Mvc (Model View Controller): Website Based Sales Information System With The Concept Of Mvc (Model View Controller)", Jurnal Mantik, 4(2), pp. 11331137. doi:

10.35335/mantik.Vol4.2020.

915. pp1133-1137.

Trimarsiah, Y., \& Arafat, M. (2017). Analisis Dan Perancangan Website Sebagai Sarana Informasi Pada Lembaga Bahasa Kewirausahaan Dan Komputer AKMI Baturaja. Jurnal Matrik. Vol. 19, No. 1, April 2017. 